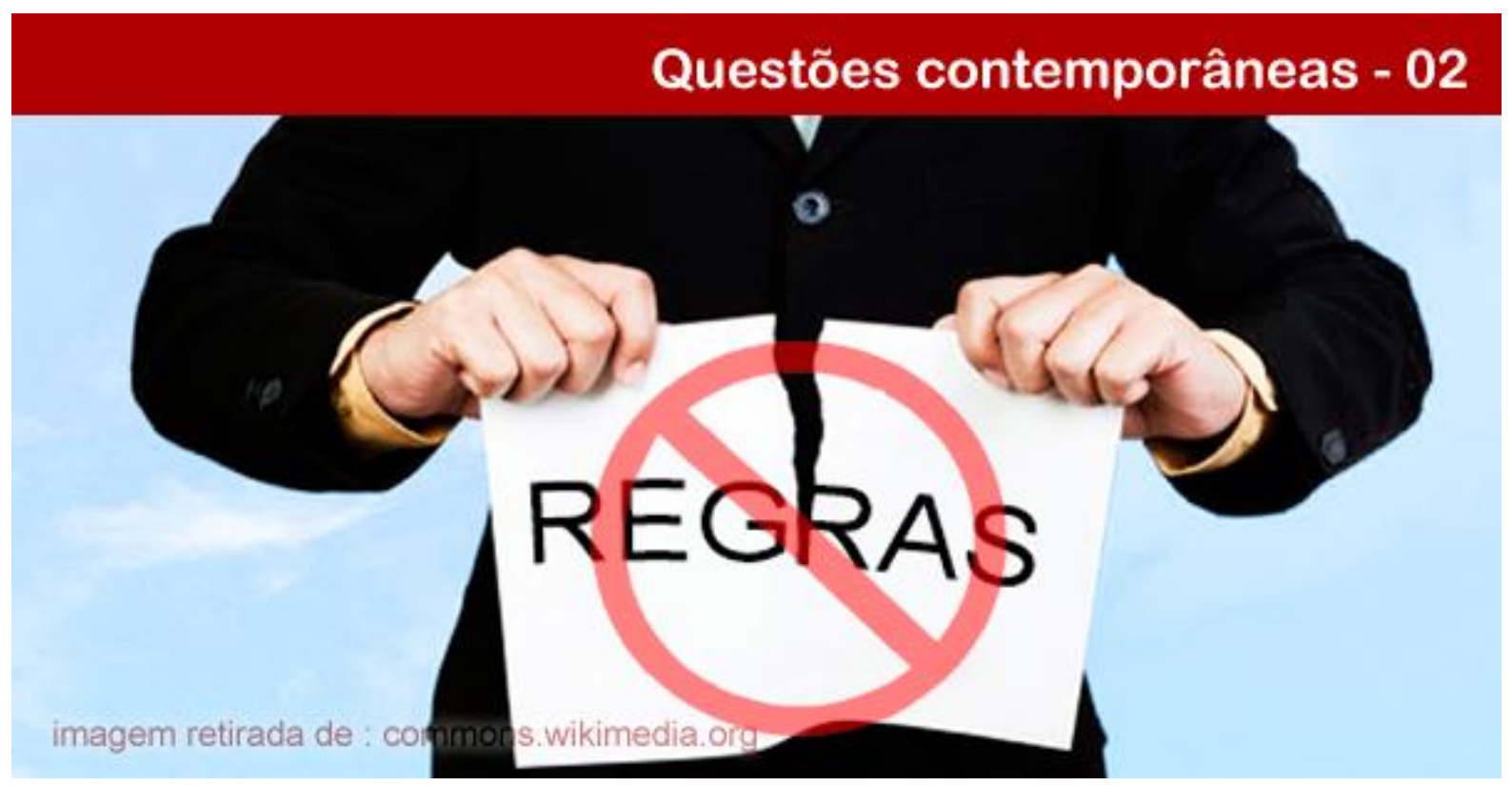

\title{
CRIANDO REGRAS APENAS PARA QUEBRÁ-LAS: UMA ANÁLISE SISTÊMICA DE TREZE PROCESSOS CONTROVERSOS DE SELEÇÃO DE DOCENTES
}

João Alberto Arantes do Amaral

Doutor em Engenharia Civil- Computação de Alto Desempenho. Professor da Universidade Federal de São Paulo (Unifesp - Campus Osasco). E-mail: joaoalberto.arantes@gmail.com.

Resumo: As regras e regulamentos criados para garantir a equidade no processo de seleção de professores para universidades públicas no Brasil às vezes falham. Realizou-se um estudo qualitativo, com abordagem de pesquisa-ação sistêmica, entrevistando 13 professores que alegam ter sido prejudicados em diferentes processos de seleção. A análise qualitativa revelou sete temas recorrentes: 1) Os membros do comitê não seguiram os procedimentos do edital; 2) Os membros do comitê agiram em favor de um candidato em detrimento dos outros; 3) Houve conluio para corrigir os resultados; 4) A seleção dos protegidos fazia parte de dinâmicas que envolviam luta pelo poder nas universidades; 5) O organizador do exame tinha vínculos comerciais, acadêmicos ou políticos com o candidato selecionado; 6) Os membros do comitê não tinham formação e nem conhecimento da área de saber exigida no exame; 7) Os candidatos prejudicados evitaram tomar ações legais contra as pessoas responsáveis pela seleção por medo de retaliação futura. Nossa análise sistêmica sugere que os processos controversos de seleção podem ser conduzidos por razões não relacionadas à excelência acadêmica, mas sim a uma luta pelo poder na academia.

Palavras chaves: Seleção. Conluio. Pesquisa-ação Sistêmica.

\section{CREATING RULES JUST TO BREAK THEM: A SYSTEMIC ANALYSIS OF THIRTEEN CONTROVERSIAL RECRUITMENT PROCESSES FOR PROFESSORSHIP IN PUBLIC UNIVERSITIES IN BRAZIL}

Abstract: The rules and regulations created to assure fairness in the selection process of professors for public universities in Brazil sometimes fail. We conducted a qualitative study, with a systemic action research approach, interviewing 13 professors that claimed to be harmed different selection processes. Seven recurrent themes emerged: 1) The committee members did not follow the edict's procedures; 2) The committee members acted in favor of one candidate to the detriment of the others; 3 ) There was collusion to fix the results; 4) The selection of protégées was part of dynamics that involve a fight for power at the universities; 5) The exam organizer had previous commercial, academic or political ties to the selected candidate; 6) The committee members did not have knowledge in the field of the exam; 7) The harmed candidates avoided taking legal action

\section{POLÊM!CA | LABORE (: (3)}

Polêmica - Revista Eletrônica da Uerj - Rua São Francisco Xavier, 524, $1^{\circ}$ andar bloco D, sl.1001 • Tels.: +55 21 2334-4088/4087 • http://www.e-publicacoes.uerj.br/index.php/polemica/index http://www.labore.uerj.br • laboreuerj@yahoo.com.br 
against the people responsible for the selection for fear of future retaliation. Our analysis suggests that controversial selection processes can be driven for reasons not related to academic excellence, but instead to a fight for power in academia.

Keywords: Recruitment. Collusio. Systemic Action Research.

\section{Introdução}

No Brasil, as universidades públicas estão em melhores posições em avaliações de universidades. Ser professor em uma dessas universidades traz toda sorte de vantagens e benefícios de um emprego público: uma carreira estável, prestígio, reconhecimento e ganhos. Para se tornar professor em uma universidade pública, o candidato deve ser selecionado em um rigoroso processo de seleção. Sempre quando é necessário, as universidades públicas brasileiras publicam editais em seus sites convidando professores a se candidatarem aos processos de seleção. Estes editais definem a posição que está disponível, os exames, os critérios de avaliação para todos os exames e a lista de tópicos para o exame escrito. Geralmente, o processo de seleção tem três exames: um exame escrito, uma prova didática e uma avaliação curricular. Cada exame é eliminatório: $\mathrm{O}$ candidato só é autorizado a fazer o exame seguinte se ele(a) for aprovado(a) no anterior. O comitê de seleção é tipicamente formado por cinco professores, um ou dois do departamento da universidade onde o cargo está sendo oferecido, e os outros de diferentes universidades.

O primeiro exame geralmente é o exame escrito. No dia do exame escrito, um tópico é selecionado aleatoriamente da lista de tópicos definida pelo edital. Normalmente, os candidatos têm três a quatro horas para escrever um ensaio sobre o tema. Os aprovados podem participar no próximo exame, a prova didática.

As regras da prova didática são simples: os candidatos têm que escolher um tópico da lista de tópicos e apresentar, no dia seguinte, uma palestra sobre o tema escolhido em 45 minutos. Os candidatos que gastam mais de 45 minutos são reprovados. Após a aula, o candidato tem que responder a perguntas propostas pelos membros do comitê sobre o assunto ministrado. Os membros do comitê dão a cada candidato uma nota baseada na avaliação de seu desempenho. Os candidatos aprovados nesta etapa podem participar do exame final.

O exame final é uma avaliação curricular. A comissão analisa o curriculum vitae dos candidatos seguindo um critério matemático de pontos e pesos. A maioria dos editais segue o "QUALIS", um sistema de classificação periódica desenvolvido pela CAPES (Coordenação de Aperfeiçoamento do Pessoal do Ensino Superior), órgão governamental vinculado ao

\section{POLÊM!CA $\mid$ LABORE}


Ministério da Educação. O comitê contabiliza o número de artigos publicados e dá uma nota a cada um. Cada artigo obtém uma nota com base na sua relevância seguindo os critérios "QUALIS". Além disso, o comitê também conta e classifica, para cada candidato, o número de artigos apresentados em congressos, o número de alunos orientados pelo candidato, o número de cursos ministrados e outras questões definidas no edital. Com base nessas avaliações, cada candidato recebe uma nota na avaliação curricular. Durante a avaliação curricular, os candidatos são entrevistados pelo comitê. O comitê faz perguntas sobre a experiência do candidato, publicações e muitos outros assuntos relacionados ao currículo. No final da entrevista, cada candidato também recebe uma nota relativa à entrevista. A nota final da avaliação curricular é uma média de ambas as notas.

Finalmente, o comitê calcula a média das notas dos candidatos em todos os três exames e dá-lhes suas notas finais. $\mathrm{O}$ candidato com o grau mais alto é escolhido. $\mathrm{O}$ processo de seleção é criado para assegurar um processo de seleção justo, garantindo que os melhores candidatos sejam selecionados para os cargos disponíveis - pelo menos em teoria. Mas como funciona na prática?

Um estudo de pesquisa dos editais de seleção de universidades públicas brasileiras apontou que os processos de seleção (SIQUEIRA et al., 2012, p.745) "podem ter fraquezas que possam comprometer os resultados". Mas quais seriam estas fraquezas?

Os autores do referido estudo (SIQUEIRA et al., 2012) sugeriram que, embora a escolha dos membros do comitê seja fundamental para o processo, os editais não definem os critérios pelos quais os membros do comitê são selecionados. Mas qual o problema em não tornar transparentes os critérios de seleção dos membros do comitê?

Um estudo realizado com 66 professores que trabalharam como membros de comitês no processo de seleção para universidades públicas brasileiras (BINOTTO et al., 2014) sugere que a escolha dos membros do comitê pode ser altamente subjetiva: os membros podem ser escolhidos não apenas com base em suas experiências em pesquisa, área de conhecimento exigida no exame, mas em função de seu relacionamento pessoal com o organizador do exame. Isso é um problema? O que os candidatos têm a dizer sobre o trabalho realizado pelos membros dos comitês?

Outro estudo realizado com 62 professores que participaram como candidatos em processos de seleção para universidades públicas brasileiras (BINOTTO et al., 2013) sugeriu

\section{POLÊM!CA $\mid$ LABORE}


que os membros do comitê podem selecionar candidatos com base em critérios pessoais altamente subjetivos ou em afinidade política ou ideológica. Além disso, o estudo também revelou que o processo de seleção pode apresentar problemas, como falta de transparência nos critérios de avaliação, subjetividade, intimidação e favoritismo. A literatura brasileira sobre esse tema é muito escassa, por isso, expandimos o escopo de nossa pesquisa para obter uma melhor compreensão da questão, tentando verificar se problemas semelhantes são descritos em outros países.

Encontramos pesquisas que apontam para a existência de favoritismo nos processos de seleção de professores na Turquia (ISMAIL, 2012). Também encontramos relatos sobre problemas nos processos de seleção enfrentados por estudiosos italianos (DURANTE et al., 2011; MOSS, 2012). Moss (2012, p.205) apontou problemas nos processos de seleção de professores em universidades italianas, tais como "abusos de poder professoral, conluio para determinar os resultados antecipadamente, favoritismo para seguidores leais, tolerância à mediocridade, indiferença ao mérito acadêmico". Além disso, também houve relatos sobre a existência de nepotismo em processos de seleção (DURANTE et al., 2011). Parece que os problemas de seleção também ocorrem nos Países Baixos. Pesquisadores (VAN DEN BRINK et al., 2010, p.1459) em um estudo de pesquisa sobre a igualdade de gênero nos protocolos de recrutamento e seleção argumentaram que "os processos de recrutamento e seleção são caracterizados por uma transparência limitada e uma responsabilidade limitada, na melhor das hipóteses". Dinâmicas similares também foram apontadas na Finlândia (HUSU, 2000).

Encontramos pesquisas sugerindo que este problema pode estar presente em todo o mundo, assumindo formas diferentes. De acordo com um estudo realizado na Austrália (MARTIN, 2009, p.4):

\footnotetext{
As práticas de patronagem acadêmica variam enormemente internacionalmente. Em alguns países, a patronagem é altamente arraigada, com professores-deuses agindo como guardiões da carreira acadêmica: ninguém sem um alto nível de endosso pessoal tem qualquer chance de progredir. Em alguns lugares, isso se torna o que se poderia chamar de corrupção, com posições universitárias comercializadas, com criação de barreiras para seleção de pessoas externas ao grupo, com graus acadêmicos outorgados a pessoas poderosas e com a escolha de acadêmicos sêniores por razões políticas e não com base em seu conhecimento acadêmico.
}

Portanto, após analisar a escassa literatura sobre o processo de seleção de professores para as universidades públicas brasileiras e a literatura sobre problemas semelhantes presentes em outros países, parece-nos que ainda há falta de informações sobre o que está por trás dos

\section{POLÊM!CA $\mid$ LABORE}


processos de seleção controversos, das dinâmicas que impulsionam a escolha dos membros do comitê e como elas impactam os procedimentos de seleção. Em nossa pesquisa, pretendemos responder a essa questão, realizando um estudo qualitativo com uma abordagem de pesquisaação sistêmica (PAS).

Para entender a abordagem PAS, devemos primeiro entender a pesquisa-ação. De acordo com Stringer (2013): "A pesquisa-ação é uma abordagem colaborativa de investigação que fornece às pessoas os meios para tomar medidas sistemáticas para resolver problemas específicos (p.8)". Bradbury (2015) salienta que os pesquisadores envolvidos em pesquisaação devem se engajar em esforços colaborativos e significativos visando contribuir para a solução de situações problemáticas e injustas que causam sofrimento, angústia ou miséria às pessoas. Em nossa pesquisa, há um ponto específico que nos interessa contribuir para melhorar: a justiça no processo seleção de professores por universidades públicas. Nós entendemos que este é um assunto que causa sofrimento para aqueles que são prejudicados por práticas desleais. Pesquisadores (BRADBURY, 2015; STRINGER, 2013) também enfatizam que a pesquisa-ação cria conhecimento através da participação das pessoas afetadas pelo problema examinado: essas pessoas devem ser incorporadas nos processos da pesquisa. Esse é o caso da nossa pesquisa: nós obtivemos a participação de professores que alegaram ter sido prejudicados por processos de seleção controversos e estavam dispostos a descrever a experiência, a refletir sobre ela e a contribuir para a pesquisa.

Uma boa maneira de aprimorar a pesquisa-ação é fazer uso de conceitos e ferramentas oriundos da área estudo de dinâmica de sistemas. Essa é a ideia central da pesquisa-ação sistêmica. Pesquisadores (VASSTRØM et al., 2008) salientam que "a pesquisa de ação sistêmica funde o pensamento sistêmico com a pesquisa-ação" (p.103). Mas como realizar isso?

Geralmente, a pesquisa-ação evolui através de uma sequência de ciclos. Tipicamente, cada ciclo tem três fases: planejamento, ação e reflexão. Fundimos o pensamento sistêmico como a fase "reflexão" de nosso ciclo de pesquisa-ação. Descrevemos esta fase como "reflexão sistêmica".

Neste artigo, discutiremos como nossa abordagem nos ajudou a verificar que os processos de seleção controversos podem ser conduzidos por razões não relacionadas à excelência acadêmica, mas sim a uma luta pelo poder na academia, onde professores

\section{POLÊM!CA $\mid$ LABORE}


poderosos (rotulados neste artigo como "padrinhos") moldam o processo, a fim de influenciar o recrutamento de candidatos por razões políticas e econômicas.

\section{Método}

Realizou-se um estudo qualitativo, com abordagem de pesquisa-ação sistêmica. Nossa pesquisa começou como uma pesquisa exploratória, evoluiu para um estudo de pesquisa descritivo-causal e, finalmente, desenvolveu-se em um estudo de pesquisa causal (Figura 1).

Inicialmente, na pesquisa exploratória, identificamos o problema através da revisão dos escassos estudos sobre os problemas relacionados aos processos de seleção de professores no Brasil. Em seguida, expandimos nossa pesquisa a fim de entender se esses problemas foram descritos em outros países, revendo artigos acadêmicos sobre o assunto. Posteriormente, realizamos dois ciclos de pesquisa-ação sistêmica (PAS).

O primeiro ciclo de PAS envolveu pesquisa descritiva-causal. Neste ciclo, planejamos encontrar e entrevistar professores dispostos a compartilhar suas experiências anteriores como candidatos em processos controversos de seleção. Criamos uma lista de professores-chave para abordar. Então, nós abordamos 30 professores, perguntando a eles se tinham participado em processos de seleção controversos como candidatos, e, em caso afirmativo, se eles estavam dispostos a compartilhar suas experiências. Dos 30 professores abordados, 13 concordaram em ser entrevistados. Realizamos entrevistas em profundidade com cada um desses professores. Pretendíamos averiguar os problemas que eles enfrentaram como candidatos e após isso revelar os temas recorrentes que emergiriam das entrevistas.

Após a realização das entrevistas, utilizamos o método de processamento de linguagem para identificar os temas recorrentes. Em seguida, realizamos uma reflexão sistêmica para determinar as conexões entre os temas. A reflexão sistêmica levou à criação de um mapa sistêmico preliminar que representou a nossa compreensão inicial do que estava por trás dos processos de seleção estudados.

Em sequência, iniciamos o segundo ciclo de PAS, uma pesquisa causal. Durante esta pesquisa procurou-se confirmar com os mesmos entrevistados se o nosso mapa sistêmico representava corretamente as dinâmicas que eles vivenciaram nos processos de seleção. Inicialmente, planejamos reuniões com eles, após isso realizamos a segunda rodada de entrevistas em profundidade e, por fim, realizamos uma segunda reflexão sistêmica para fazer

\section{POLÊM!CA $\mid$ LABORE}


os ajustes necessários no mapa sistêmico criado. O mapa sistêmico final foi usado como referência para a seção de discussão deste artigo.

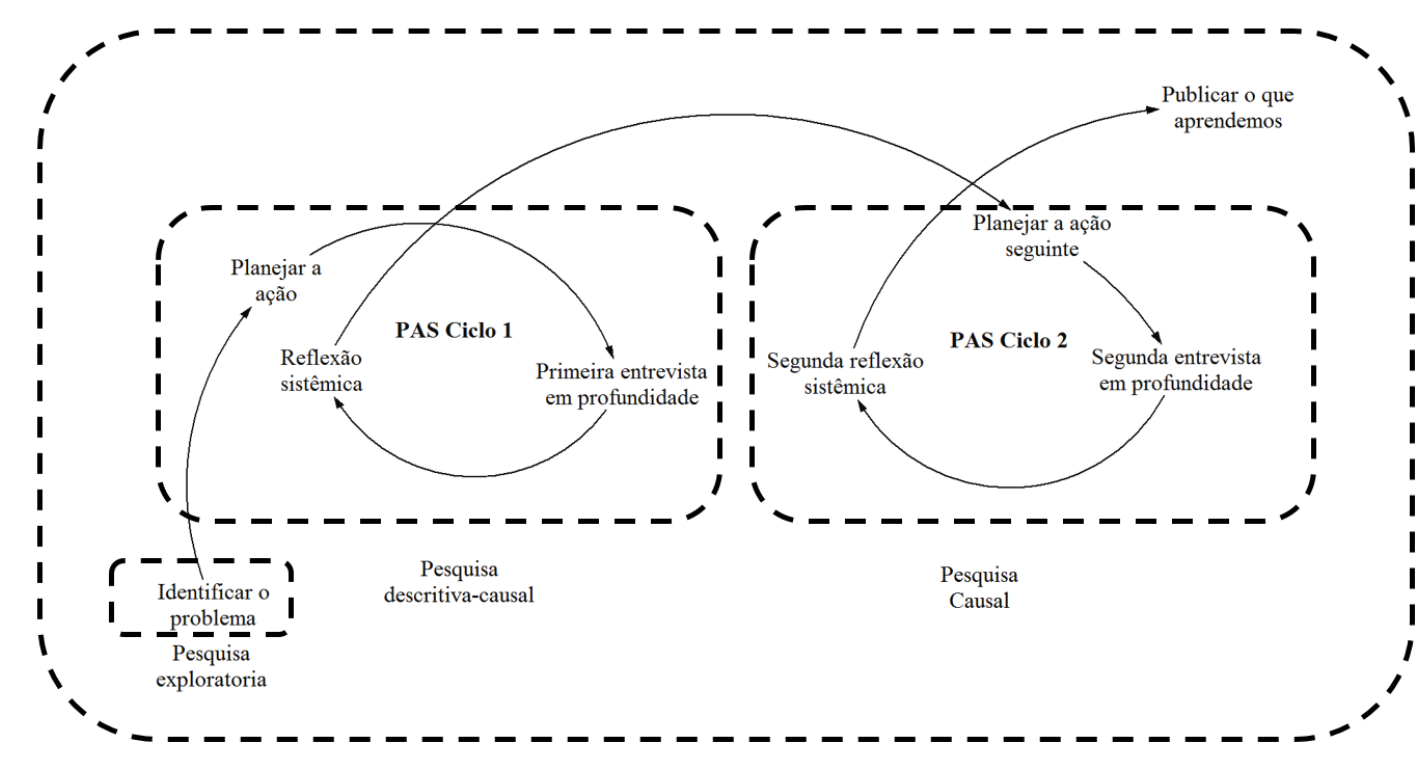

Figura - 1: O método de pesquisa seguido. Fonte: $\mathrm{O}$ autor.

\section{Resultados}

Os 13 participantes do estudo são agora professores em universidades públicas. Sete são do sexo masculino e seis do sexo feminino. Todos eles são brasileiros, e todos têm doutorado. Em média, cada um participou em dois processos de seleção antes de ser aprovado em um terceiro processo de seleção. Da análise dos textos das entrevistas em profundidade, descobrimos sete temas recorrentes (TR) que caracterizaram os processos de seleção controversos:

1) Os membros do comitê não seguiram os procedimentos descritos no edital

2) Os membros do comité agiram a favor de um candidato em detrimento dos outros

3) Houve conluio entre o organizador do exame e os membros do comitê para determinar os resultados

4) A seleção de protegidos foi apenas parte de uma dinâmica complexa que envolveu uma luta por poder e influência nas universidades

5) $\mathrm{O}$ organizador do exame teve laços comerciais e/ou acadêmicos anteriores com o candidato selecionado

\section{POLÊM!CA $\mid$ LABORE}


6) Os membros do comitê não tinham formação e nem conhecimento da área de saber exigida no exame

7) Os candidatos prejudicados evitaram tomar ações legais contra as pessoas responsáveis pela seleção por medo de retaliação futura.

\section{TR1: Os membros do comitê não seguiram os procedimentos descritos no edital}

Os entrevistados relataram problemas relacionados à não-conformidade com as regras gerais de edital de seleção. Um problema estava relacionado ao calendário dos exames. $\mathrm{O}$ Entrevistado 5, homem, deu-nos um exemplo:

$O$ exame escrito foi definido nas regras do edital para começar na hora " $X$ ". No entanto, o exame não iniciou no horário agendado. Só começou uma hora depois. Os membros do comitê estavam deliberadamente aguardando a chegada de um candidato, que estava atrasado. Quando o candidato finalmente chegou, o exame começou. Coincidentemente, este candidato foi o escolhido.

Uma das principais regras definidas em todos os editais para o processo de seleção do professor é a que os membros do comitê não devem ter publicado artigos em parceria com nenhum dos candidatos. No entanto, o Entrevistado 4, mulher, descreveu que esta regra foi quebrada no processo de seleção em que participou:

No comitê havia um membro que tinha publicado três artigos com um candidato. Adivinha quem foi o candidato escolhido? Este candidato!

TR2: Os membros do comitê agiram em favor de um candidato em detrimento dos outros

Os entrevistados também relataram sobre a atitude tendenciosa dos membros do comitê. Muitos tipos de práticas desleais foram descritos, como questionamentos agressivos, desdém e desrespeito. O Entrevistado 3, mulher, descreveu os detalhes da situação que enfrentou:

Na prova didática, eu percebi (com muita angústia) que um dos membros do comitê estava dormindo durante a minha apresentação. Sim, ele estava dormindo, você acredita nisso! Ele dormiu por quase 20 minutos. Depois da minha apresentação, o mesmo professor fez severas críticas à palestra que eu dei.

O Entrevistado 10, homem, deu um exemplo de comportamento agressivo que enfrentou:

Durante a prova didática, o presidente do comitê claramente exibiu irritação com a minha apresentação. Depois que as notas foram dadas por todos os membros da comissão, eu pedi para ver as avaliações. Para minha surpresa, eu vi que o meu formulário de avaliação tinha marcas grotescas de rasuras, sinais claros que os

\section{POLÊM!CA $\mid$ LABORE}

Polêmica - Revista Eletrônica da Uerj - Rua São Francisco Xavier, 524, $1^{\circ}$ andar bloco D, sl.1001 • Tels.: +55 21 2334-4088/4087 • http://www.e-publicacoes.uerj.br/index.php/polemica/index http://www.labore.uerj.br • laboreuerj@yahoo.com.br 
outros avaliadores rebaixaram as pontuações que deram para mim, a fim de fazer com que suas notas ficassem mais próximas das notas dadas pelo presidente do comitê.

Houve também relatos de membros do comitê tratando os candidatos de maneira diferente. O Entrevistado 11, mulher, descreveu uma situação que enfrentou:

\begin{abstract}
No meu exame, havia apenas dois candidatos, eu e outra mulher. Os membros do comitê mostraram ostensivamente preferência por ela. Em todas as fases do exame, os membros da comissão se comportaram como se estivessem celebrando sua vitória, com abraços, beijos e palavras gentis. Por outro lado, eles me tratavam de maneira muito formal, com frieza e distância. Obviamente, a outra candidata foi escolhida. Foi uma experiência devastadora. Eu deixei o exame em lágrimas!
\end{abstract}

Os entrevistados também relataram que havia tolerância para a mediocridade acadêmica e indiferença ao mérito acadêmico. O Entrevistado 2, homem, explicou:

\begin{abstract}
No processo de seleção em que participei, houve um claro exemplo de como a comissão agiu com preconceito: entre os candidatos, havia três candidatos fortes com um número significativo de artigos publicados em revistas conceituadas, $e$ muitos anos de prática como professor. O candidato escolhido não tinha nenhum artigo publicado e nenhuma experiência didática. Mas o organizador do exame foi seu orientador de pós-graduação. Logo, este candidato foi o escolhido.
\end{abstract}

\title{
TR3: Houve conluio entre o organizador do exame e os membros do comitê para determinar
}

\section{os resultados}

Os entrevistados descreveram que os membros do comitê tinham vínculos estreitos com o organizador do exame. O Entrevistado 7, mulher, explicou:

\begin{abstract}
No departamento " $A$ " da universidade "B", todos os processos de seleção foram organizados pelo mesmo professor: Ele sempre convidou professores de um mesmo grupo de seus amigos para se tornarem membros do comitê. Às vezes, ele se revezava, substituindo um professor por outro, para evitar tornar o processo injusto tão evidente. Hoje em dia, a maioria dos candidatos escolhidos nos exames de seleção organizados por ele, são professores de seu departamento. Estes professores são seus seguidores leais. Aqueles que não fazem parte de seu grupo de apoiadores são constantemente hostilizados por ele.
\end{abstract}

O Entrevistado 8, homem, apontou ações do organizador do exame para influenciar os membros do comitê:

Na manhã do exame, o organizador do exame entrou na sala onde os membros do comitê estavam se reunindo e ficou lá por meia hora. Naquela época, eu não sabia o motivo. Meses após o exame, um ex-membro da comissão me disse que o organizador do exame estava lá para influenciar os membros da comissão, para verificar se os membros estavam dispostos a escolher o candidato que o organizador escolhera.

O Entrevistado 6, homem, declarou ter participado de um exame de seleção, apesar de saber que suas chances de ser aprovado eram bastante pequenas. Ele explicou que isso se

\section{POLÊM!CA $\mid$ LABORE}

Polêmica - Revista Eletrônica da Uerj - Rua São Francisco Xavier, 524, $1^{\circ}$ andar

bloco D, sl.1001 • Tels.: +55 21 2334-4088/4087 • http://www.e-publicacoes.uerj.br/index.php/polemica/index http://www.labore.uerj.br • laboreuerj@yahoo.com.br 
deveu ao procedimento sistemático seguido pelo chefe do departamento desta universidade (a pessoa encarregada de organizar os exames). Ele descreveu os procedimentos:

\begin{abstract}
Eu fiz meu doutorado no departamento encarregado do exame de seleção. Enquanto eu era um estudante de pós-graduação, o chefe do departamento não fazia nenhum segredo sobre como ele comandava o departamento. Uma vez que ele explicou aos estudantes de pós-graduação que, para se tornar um professor do "seu" departamento, a pessoa tinha que ser escolhida por ele e "esperar anos em uma fila." Segundo ele, o primeiro processo de seleção seria feito para selecionar candidato A, a próxima seleção era para selecionar o candidato $B$, e assim por diante. Eu não fui selecionado, claro. O candidato A, o primeiro na fila, foi escolhido.
\end{abstract}

TR4: A seleção dos protegidos fazia parte de dinâmicas que envolviam luta pelo poder nas $\underline{\text { universidades }}$

Os entrevistados relataram que a seleção de protegidos era apenas uma parte de uma situação complexa que envolvia luta pelo poder e influência na universidade. Nossos entrevistados conjecturaram que alguns membros da comissão deram seu apoio a determinado candidato em troca de apoio futuro para seus próprios objetivos. Outros suspeitavam que os membros do comitê deram seu apoio como compensação por favores passados. Segundo eles, professores com um grande número de aliados podem se tornar muito poderosos. Os entrevistados especularam que o processo de seleção pode ser uma forma de conquistar apoiadores leais a longo prazo. O Entrevistado 12, homem, explicou sua compreensão desta questão:

Nas universidades públicas brasileiras, quase tudo é decidido por votos. Os professores com maior número de apoiadores leais são capazes de assumir posições-chave na universidade: isto lhes dá poder suficiente para influenciar (positivamente ou negativamente) a carreira de outros professores. O poder não tem nada a ver com conquistas acadêmicas: o poder tem a ver com o apoio político! Os grupos dominantes estabelecem as regras acadêmicas e administrativas. Portanto, parece que é muito importante, para aqueles com ambições políticas, selecionar cuidadosamente seus futuros apoiadores.

O Entrevistado 13, mulher, teve uma visão similar do problema:

Os professores em posições-chave (tais como diretores, chefes de câmaras acadêmicas, chefes de departamentos, chefes de comissões) com apoiadores leais têm o poder de definir (ou pelo menos influenciar) quase todos os aspectos da vida acadêmica, como definir regras, autorizar professores a estudar no exterior em atividades de pós-doutorado, definir quem será o responsável pelas comissões mais desejadas e quem será responsável pelas comissões não desejadas (tais como investigações, licitações, processos investigativos etc.) Professores poderosos podem tornar a vida mais fácil para seus apoiadores e tornar a vida miserável para seus adversários.

\title{
POLÊM!CA $\mid$ LABORE
}

Polêmica - Revista Eletrônica da Uerj - Rua São Francisco Xavier, 524, $1^{\circ}$ andar

bloco D, sl.1001 • Tels.: +55 21 2334-4088/4087 • http://www.e-publicacoes.uerj.br/index.php/polemica/index http://www.labore.uerj.br • laboreuerj@yahoo.com.br 
O Entrevistado 2, homem, destacou que professores poderosos com apoiadores leais também podem ter posições-chave nas fundações universitárias. Ele explicou:

As fundações universitárias permitem aos professores fazer projetos de consultoria para grandes empresas. As fundações podem proporcionar renda extra aos professores; isto pode multiplicar seu salário muitas vezes. Muitos professores desejam ter posições-chave nas fundações para controlar os projetos e distribuir os recursos de acordo com suas vontades. No entanto, apenas aqueles com grande número de apoiadores podem obter tais posições. Os processos de seleção são os meios que professores poderosos usam para criar seu grupo de apoiadores.

TR5: O organizador do exame tinha vínculos comerciais, acadêmicos ou políticos com o $\underline{\text { candidato selecionado }}$

Os entrevistados descreveram sua suspeita de que, em alguns casos, o candidato escolhido no processo de seleção tinha uma relação anterior com o organizador do exame. Existem três tipos de relações descritas: relações comerciais, relações acadêmicas e afinidade política. O Entrevistado 1, mulher, explicou:

$O$ organizador do exame e o candidato selecionado tiveram um relacionamento comercial e acadêmico de longa duração, eles trabalharam juntos por mais de dez. anos antes do exame. $O$ organizador do exame foi o chefe do candidato em um curso de MBA pago oferecido por uma fundação da universidade responsável pelo exame. $O$ organizador do exame também foi o orientador de tese do candidato. E, para piorar as coisas, após o exame, o candidato escolhido foi selecionado para uma posição-chave nesta fundação. É escandaloso!

O Entrevistado 2, homem, descreveu uma situação semelhante que ocorreu durante um exame em outra universidade. Explicou a relação comercial entre o organizador do exame e o candidato selecionado. Suspeitou que o organizador do exame aprovou o candidato como a compensação para um negócio anterior:

Um dia, descobri a relação entre o candidato escolhido e o organizador do exame: antes do exame, o organizador do exame tinha trabalhado durante anos como consultor para a empresa de consultoria cujo proprietário era o candidato!

O Entrevistado 9, homem, destacou a importância dos laços políticos:

No Departamento "A" da Universidade "B", todos os professores têm a mesma ideologia e preferência política. A maioria deles trabalhou (ou tem laços estreitos) com o partido político " $C$ ". Isso é apenas uma coincidência? Estou certo de que não é o caso. Dê uma olhada nos comitês dos processos de seleção anteriores: todos os membros eram ativistas políticos ou partidários do partido "C"! E quem era o organizador do exame? Sempre o mesmo professor!

TR6: Os membros do comitê não tinham formação e nem conhecimento da área de saber exigida no exame

\section{POLÊM!CA $\mid$ LABORE}

Polêmica - Revista Eletrônica da Uerj - Rua São Francisco Xavier, 524, $1^{\circ}$ andar

bloco D, sl.1001 • Tels.: +55 21 2334-4088/4087 • http://www.e-publicacoes.uerj.br/index.php/polemica/index http://www.labore.uerj.br • laboreuerj@yahoo.com.br 
Os entrevistados também relataram a falta de relação entre a área de saber exigida no exame e os conhecimentos dos membros do comitê. O Entrevistado 6, homem, explicou o que aconteceu em um exame, na área de Estatística:

Dois membros do comitê eram médicos e enfermeiros, sem conhecimento comprovado na área do exame! Também ficou claro para mim que até o membro do comitê, que era um matemático, não tinha os conhecimentos na área exigida no exame!

Além disso, o Entrevistado 2, homem, destacou:

As perguntas que os membros do comitê me fizeram após a minha aula foram ridículas: ficou claro para mim que eles não tinham ideia sobre o tema do exame! Um deles pediu desculpas para mim, dizendo que embora soubesse muito pouco sobre o assunto, ele ia fazer perguntas de qualquer maneira ...

TR7: Os candidatos prejudicados evitaram tomar ações legais contra as pessoas responsáveis pela seleção por medo de retaliação futura.

Todos os entrevistados expressaram medo de falar sobre os polêmicos processos de seleção. O Entrevistado 2, homem, explicou:

Se você processar as pessoas responsáveis por exames controversos, você nunca vai passar em exames futuros oferecidos por universidades públicas. Você será rotulado como um "dedo-duro"; você nunca vai conseguir um emprego como professor; esqueça isso! É como a máfia: eles nunca vão te perdoar!

Alguns dos entrevistados expressaram que tinham medo de retaliação pelo organizador do exame, que às vezes ainda mantinha posições poderosas nas universidades. O Entrevistado 3, mulher, expressou seus sentimentos:

Pelo amor de Deus, esta é uma entrevista anônima, ok? Se o professor X e seu grupo de apoiadores descobrirem que eu conversei com você sobre o processo de seleção de sua protegida, eles vão fazer da minha vida um inferno!

\section{Discussão}

É um conhecimento comum dos pensadores sistêmicos que a estrutura de um sistema é responsável por seu padrão de comportamento (SENGE, 1990; STERMAN, 2000). Nesta seção, discutiremos as estruturas sistêmicas que levam aos padrões de comportamento presentes nos controversos processos de seleção estudados.

A reflexão sistêmica realizada no ciclo PAS 1 permitiu compreender as conexões entre TR1 (os membros do comitê não seguiram os procedimentos descritos no edital), TR2 (os membros do comitê agiram em favor de um candidato em detrimento dos outros) e TR3 (Houve conluio entre o organizador do exame e os membros do comitê para determinar os

\section{POLÊM!CA $\mid$ LABORE}

Polêmica - Revista Eletrônica da Uerj - Rua São Francisco Xavier, 524, $1^{\circ}$ andar

bloco D, sl.1001 • Tels.: +55 21 2334-4088/4087 • http://www.e-publicacoes.uerj.br/index.php/polemica/index

http://www.labore.uerj.br • laboreuerj@yahoo.com.br 
resultados). Ao analisar cuidadosamente as entrevistas, ficou claro que o conluio para determinar os resultados foi o motivo que levou às ações subsequentes (intimidação, avaliações injustas, violação das regras de seleção, tolerância à mediocridade, indiferença ao mérito acadêmico) tomadas pelos membros do comitê que levaram à seleção dos protegidos (Figura 2).

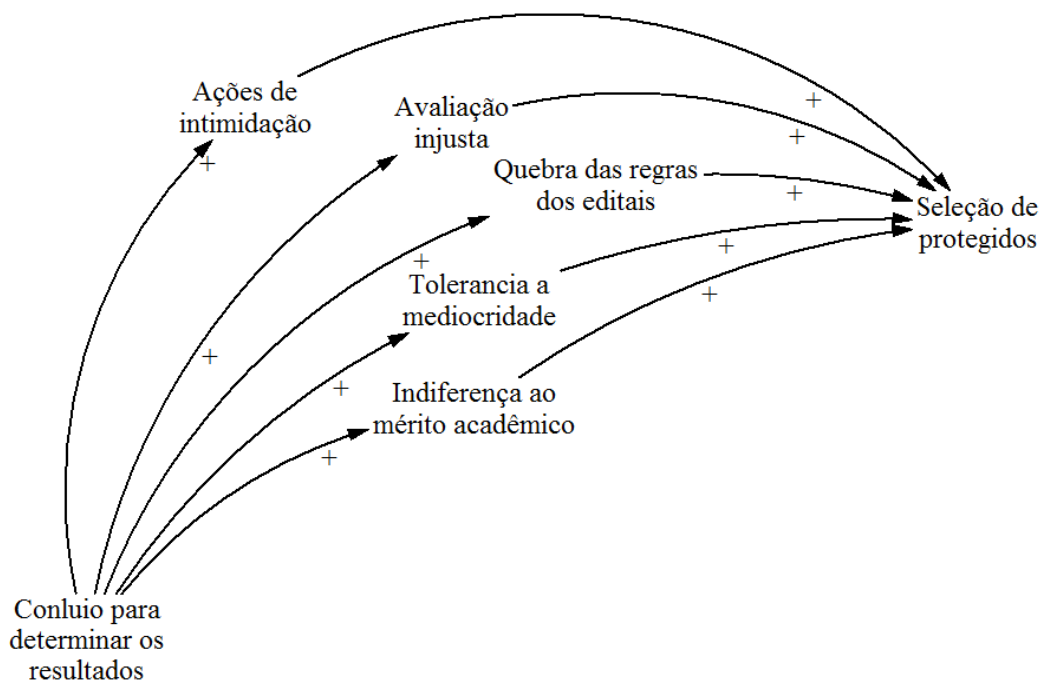

Figura - 2: $\mathrm{O}$ conluio para determinar os resultados leva o comitê a realizar práticas injustas. Fonte: $\mathrm{O}$ autor.

No entanto, naquele ponto da pesquisa, as razões para a criação do conluio ainda não estavam claras para nós. O ciclo de PAS 2 permitiu-nos entender as razões: durante este ciclo, TR4 (A seleção de protegidos era apenas parte de uma dinâmica complexa que envolvia luta por poder e influência na universidade), TR5 (O organizador do exame tinha vínculos comerciais, acadêmicos ou políticos com o candidato selecionado), TR6 (Os membros do comitê não tinham formação e nem conhecimento da área de saber exigida no exame) e TR7 (Os candidatos prejudicados evitaram tomar ações legais contra as pessoas responsáveis pelos processos de seleção controversos por medo de retaliação futura) surgiram.

Com base nas respostas dos entrevistados, pudemos entender quatro dinâmicas de poder na academia que podem ter influenciado os processos de seleção estudados (Figura 3).

\section{POLÊM!CA $\mid$ LABORE}




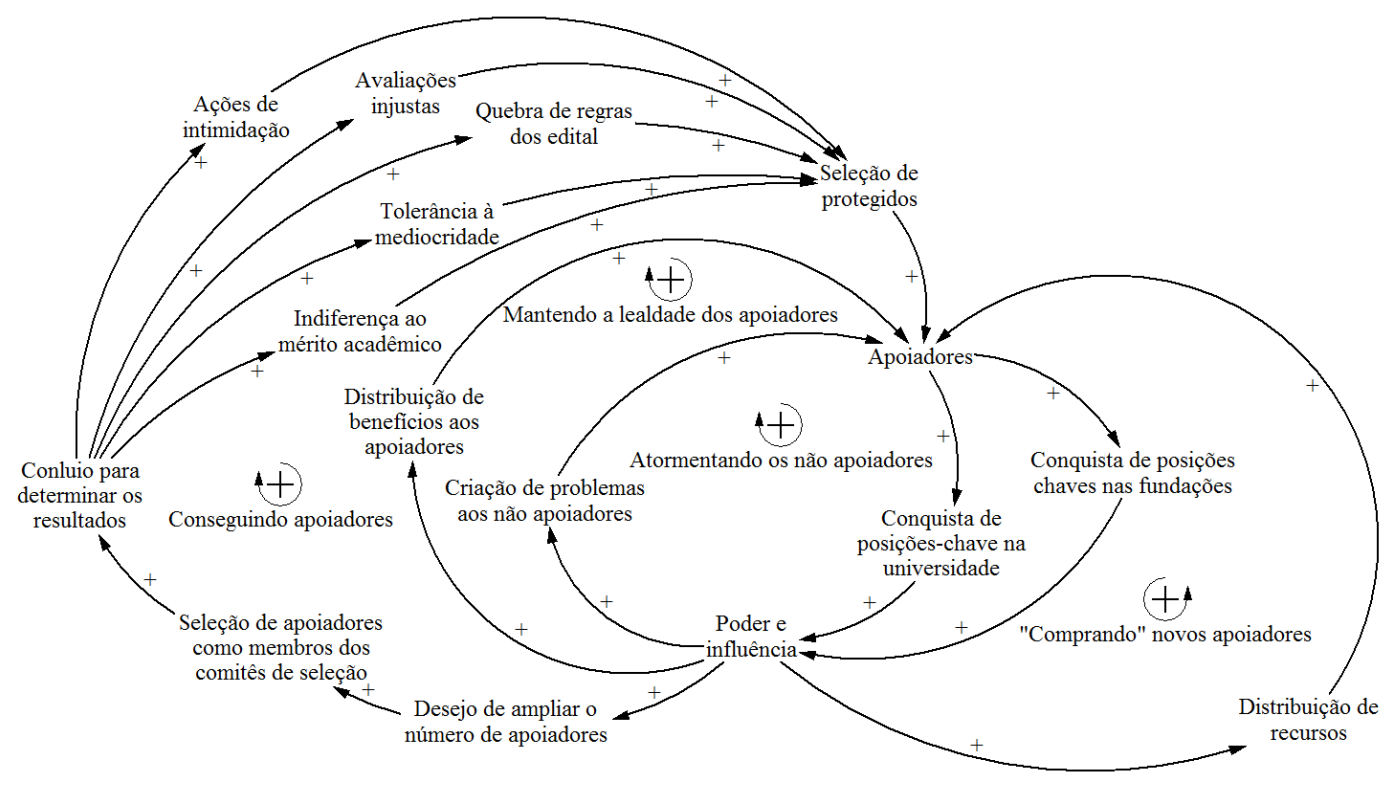

Figura - 3: As dinâmicas responsáveis pelos processos de seleção controversos. Fonte: O autor.

Nós denominamos essas dinâmicas como "Conseguindo apoiadores", "Mantendo a lealdade dos apoiadores", "Atormentando os não-apoiadores" e "Comprando novos apoiadores".

Analisando os TR4 e TR5, parece-nos que a seleção de protegidos é o meio mais eficiente que os professores que procuram o poder a todo custo (doravante os chamamos de "padrinhos") usam para aumentar seu grupo de apoiadores. Essa dinâmica (representada na Figura 3 pelo ciclo "Conseguindo apoiadores") pode explicar a importância de selecionar membros do comitê que seguirão os desejos dos padrinhos. A seleção de alguém com quem o padrinho tem laços (como apontado pela TR5) parece ser uma troca de favores: O padrinho dá ao protegido uma cátedra, e em troca disso, o protegido dará apoio aos objetivos políticos do padrinho.

Esta dinâmica também pode explicar os problemas trazidos à tona pela TR6: parece que a seleção dos membros do comitê pode ter pouco a ver com a experiência do membro, mas está mais relacionada à sua lealdade ao padrinho.

TR4 também nos ajudou a compreender que manter apoiadores leais é tão importante quanto selecionar os apoiadores. Com base nas entrevistas, parece que, à medida que o padrinho se torna mais poderoso, ele/ela pode distribuir recompensas para os apoiadores

\section{POLÊM!CA $\mid$ LABORE}


(ciclo "Mantendo a lealdade dos apoiadores", Figura 3) e pressionar os não apoiadores a se tornarem apoiadores (ciclo “Atormentando os não apoiadores”, Figura 3).

TR4 sugere que ter apoiadores é um meio que o padrinho pode usar para alcançar posições-chave em fundações universitárias. Ter posições-chave nestas fundações pode aumentar o poder do padrinho, permitindo-lhe distribuir recursos aos apoiadores (Figura 3, ciclo "Comprando novos apoiadores").

TR7 ajudou-nos a entender por que, uma vez que essas dinâmicas são estabelecidas, eles podem se enraizar, tornando difícil de combate-las. À medida que os padrinhos se tornam mais poderosos, eles podem usar seu poder para retaliar contra aqueles que ousam desafiar sua posição de liderança.

Finalmente, o nosso estudo sugere que, apesar das pequenas diferenças entre os processos controversos estudados, parece que as dinâmicas por trás de todos os processos de seleção estudados foram bastante semelhantes: os processos de seleção parecem ter sido criados apenas para servir os interesses dos padrinhos.

Os protegidos foram escolhidos pelos padrinhos muito antes dos exames, e os membros do comitê foram então selecionados entre os apoiadores dos padrinhos, a fim de tornar possível alcançar os resultados desejados. O edital foi criado para dar a um processo ilegítimo uma aparência legítima. A subjetividade da classificação foi a ferramenta usada pelos comitês para descartar os candidatos indesejáveis.

Embora este estudo possa ter implicações importantes para a compreensão das dinâmicas presentes em processos de seleção polêmicos, existem limitações sobre as quais devemos refletir. Focamos nossa pesquisa nas entrevistas realizadas com 13 professores que estavam dispostos a compartilhar o seu ponto de vista sobre situações que enfrentaram em diferentes processos de seleção. Portanto, as dinâmicas analisadas talvez não possam ser generalizadas para outros contextos. Reconhecemos que muitos processos de seleção em universidades públicas brasileiras podem não ter os problemas abordados aqui. Também reconhecemos que os candidatos não escolhidos durante o recrutamento acadêmico podem ter opiniões tendenciosas sobre os processos em si. No entanto, colocar uma luz sobre os problemas pode ser uma maneira útil de entender a importância de criar um sistema de pesos e contrapesos a fim de evitar que professores poderosos moldem processos de seleção de acordo com suas vontades.

\section{POLÊM!CA $\mid$ LABORE}




\section{Considerações finais}

Apesar de todas as limitações do nosso estudo, pensamos que a nossa abordagem de pesquisa-ação pelo menos ajudou os professores que alegaram ter sido prejudicados no processo de seleção a serem ouvidos. Os processos de seleção em que participaram trouxeram angústia e dor. Discutir e refletir com eles os aspectos sistêmicos dos problemas enfrentados é uma maneira de amenizar sua dor. Consideramos que uma análise sistêmica desses concursos controversos também pode ser útil para os formuladores de políticas educacionais, permitindo que eles obtenham subsídios para preparar regras mais rígidas para tornar a seleção dos membros do comitê transparente e o processo de avaliação menos sujeito à subjetividade. A criação de auditorias externas que avaliem a equidade do processo de seleção e o trabalho realizado pelos membros dos comitês também pode ser útil. Esperamos que este artigo possa lançar luz sobre uma questão que pode estar causando muito sofrimento a diversos candidatos.

\section{Referências}

BINOTTO, E.; et al. A Experiência dos docentes aprovados e reprovados na seleção de docentes em universidades federais. In: III COLOQUIO DE GESTIÓN UNIVERSITARIA EN AMÉRICAS, 2013, Florianópolis. Anais Eletrônicos...Florianópolis: UFSC. Disponível em :

<https://repositorio.ufsc.br/handle/123456789/114712?show=full:2013>, Acesso em: 26 maio 2017.

BINOTTO, E.; et al. O Desafio da Escolha e as Atribuições da Banca na Seleção Docente nas Universidades Federais. Planejamento e Políticas Públicas, Brasília, v.43, p. 225-249, jul./dez., 2014.

BRADBURY, H. The Sage handbook of action research. Los Angeles: Sage, 2015.

DURANTE, R.; LABARTINO, G.; PEROTTI, R. Academic dynasties: Decentralization and familism in the Italian academia. The National Bureau of Economic Research, Cambridge, nov.2011. Disponível em:< http://www.nber.org/papers/w17572.pdf.>. Acesso em:26 maio 2017.

HUSU, L. Gender discrimination in the promised land of gender equality. Higher Education in Europe, Londres, v.25,n. 2, p. 221-228, jul., 2000.

ISMAIL, A. The existence of favoritism in organizations. African Journal of Business Management, Joanesburgo, v.6, n.12, p. 4577-4586, jan., 2012.

MARTIN, B. Academic patronage. International Journal for Educational Integrity, Londres, v.5, n. 1, p. 319, jun., 2009.

MOSS, D. When patronage meets meritocracy: Or, the Italian academic concorso as cockfight. European Journal of Sociology, Nanterre, v.53, n.2, p. 205-231, ago., 2012.

SENGE, P. The fifth discipline: The art and science of the learning organization. Nova York: Currency Doubleday, 1990.

\section{POLÊM!CA $\mid$ LABORE}


SIQUEIRA, E. S; et. al. Seleção de Docentes em Universidades Federais: uma análise dos regulamentos. Revista Ensaio: Avaliação e Políticas Públicas em Educação, Rio de Janeiro, v. 20 n.77, p. 725-748, out./dec., 2012.

STERMAN, J.D. Business dynamics: Systems thinking and modeling for a complex world. Boston: Irwin McGrawHill, 2000.

STRINGER, E. T. Action research. Thousand Oaks: Sage Publications, 2013.

VAN DEN BRINK, M., BENSCHOP, Y., JANSEN, W.Transparency in academic recruitment: A problematic tool for gender equality? Organization Studies, Amsterdam, v31, n.11, p. 1459-1483, maio, 2012.

VASSTRØM, M.; et al. Facilitating agricultural innovation and learning through systemic action research. In: PROCEEDINGS FROM $10^{\mathrm{TH}}$ ANNUAL CONFERENCE, NORDIC-SCOTTISH FOR RURAL AND REGIONAL DEVELOPMENT, 2008, Copenhagen Anais Eletrônicos...Copenhagen: University of Copenhagen, Disponível em:

<https://www.researchgate.net/profile/Hanne_Tanvig/publication/230583307_Innovation_Systems_and_Rural_ Development/links/544a1fec0cf2f6388084f43f.pdf >, Acesso em: 26 maio 2017.

Recebido em: 13/02/2017.

Aceito em: 01/06/2017.

\section{POLÊM!CA $\mid$ LABORE}

Polêmica - Revista Eletrônica da Uerj - Rua São Francisco Xavier, 524, $1^{\circ}$ andar bloco D, sl.1001 • Tels.: +55 21 2334-4088/4087 • http://www.e-publicacoes.uerj.br/index.php/polemica/index http://www.labore.uerj.br • laboreuerj@yahoo.com.br 